\title{
Os poderes na França. Os Espelhos de Príncipes e suas construções sobre a importância régia nos séculos finais do medievo francês.
}

Ricardo Fontes dos Santos de Assis*

Resumo: Espelho de Príncipes é um gênero tratadista tido como uma dos mais importantes produzidos no final do medievo francês. Por meio de uma narrativa normativa foram construídos modelos de governantes ideais. Desta forma, este estudo analisa uma parcela deste discurso com o fim de apresentar a importância do texto nas considerações e construções sobre o poder.

Palavras-chaves: Espelho de Príncipes; monarquia francesa; Baixa Idade Média

Abstract: One of the most important treatises genres produced by the end of the French medieval age was the known Mirrors of Princes, which through a normative narrative have constructed their ideal governance models. This article analyses a part of the discursive modality aiming at recognizing its importance for that period in terms of its possible considerations and constructions about power.

Keywords: Mirror of Princes; French Monarchy, Late Middle Age

\section{Introdução}

A década de 1370 marcou profundamente a história do pensamento sobre o poder na França. As traduções da Política de Aristóteles por Nicolau Oresme, em 1376, e do Songe du Vergier por Raul Presles, em 1378, ambas solicitadas por Carlos V, contribuíram para que se desencadeassem mudanças nos pressupostos sobre a prática governativa. Se até este momento a produção normativa estava restrita ao latim e concentrada nas mãos de eclesiásticos, as traduções destas duas obras para o francês estimularam os letrados de corte ao debate sobre a autonomia dos poderes régios. A partir daí, aumenta acentuadamente a produção escrita no reino da França, especificamente de tratados que discorrem sobre as ações de poder e sobre a imagem do governante.

Foi, portanto, na segunda metade do século XIV, mais especificamente a partir do reinado de Carlos V (1364-1380), que a maioria dos homens que pensaram os poderes passou a se concentrar na produção de obras que, fundamentalmente, apresentavam modelos

\footnotetext{
* Mestre em História pelo Programa de Pós-Graduação em História da Universidade Estadual Paulista Júlio de Mesquita Filho (UNESP), Campus de Franca. Pesquisa financiada pela Fundação de Amparo à Pesquisa do Estado de São Paulo (FAPESP). Contato: riccofontes@ hotmail.com
} 
virtuosos de boa governação. O principal motivo desse aumento significativo da produção escrita sobre a prática e a moral política dos governantes no período em que reinou este monarca está em seu empenho para preencher sua corte e os cargos burocráticos do Estado com homens que eram detentores de saber, tais como juristas, matemáticos, filósofos, astrólogos, artífices, médicos e muitos outros oriundos das universidades medievais ou de outros reinos do Ocidente.

A proposta com este artigo é apresentar como os letrados desse período contribuíram diretamente com suas produções normativas, em especial os Espelhos de Príncipe, para reformular as estruturas políticas e de poder na França do final do medievo francês, com maior atenção em Philippe de Mézières e Christine de Pisan, dois letrado que propuseram modelos de governação inspirados no reinado e figura de Carlos V.

\section{Tratados Pedagógicos e Normativos no Final do Medievo.}

No final da Idade Média, foram formulados escritos normativos e pedagógicos nos quais se discutiram e se estabeleceram normas de conduta para uma boa governação em muitos dos reinos da Europa medieval. A França, em especial a partir do século XIII, foi um dos mais importantes palcos desta modalidade escrita, justamente por ter sido responsável por um relevante número de escritos. Além disso, porque muitos dos mais influentes homens que pensaram o poder eram franceses - ou se formaram e trabalharam em instituições universitárias francesas.

Naquele período, os tratados se apresentavam de diversas formas: havia aqueles direcionados às condutas dos homens no interior das cortes ou no trato com suas famílias; outros, em menor número, eram endereçados às mulheres a fim de ditar seus papeis dentro da sociedade da época. Dentre estes escritos pedagógicos, um dos gêneros mais relevante produzido foram os conhecidos Espelhos de Príncipe, nos quais se apresentavam modelos ideais de governança para os homens de seu tempo a partir da descrição da moral e da vida política de governantes do passado reconhecidos como virtuosos.

Os Espelhos não foram construções textuais próprias dos séculos finais da Idade Média. Suas primeiras elaborações constam da época do reinado de Carlos Magno (séculos VIII e IX), que ganharam importância como instrumentos de edificação e afirmação dos poderes, tanto secular como eclesiástico, ao longo dos séculos seguintes. As atribuições e a legitimação dos poderes eram fontes de interesse dos homens que pensaram a organização dos reinos desde o século XII - um exemplo é o célebre Policraticus. Nesses séculos finais do 
medievo, uma produção escrita destinada às ações governativas destacou a constituição de verdadeiras formas híbridas dos poderes, consolidadas ao longo desses séculos e envolvendo empréstimos mútuos entre as esferas (Cf. KANTOROWICZ, 1998: 125).

Especificamente no que diz respeito às forças seculares, estas "trocas" eram estabelecidas como representação de uma comunidade unificada, cristã e "nacional". Nesse sentido, Vicente de Beauvais no século XIII, definiu o Estado como um "corpus reipublicae mysticum", "(...) um caso claro de termos emprestados das abundantes idéias eclesiásticas, e de transferência, para a república secular (...)", seguido por seu contemporâneo Gilbert Tournai que, valendo-se da mesma expressão, "corpus mysticum”, definiu seu modelo de perfeito governante como verdadeiro representante de Deus, cabendo ao papado apenas a orientação espiritual dos corpos terrestres (Cf. KANTOROWICZ, op. cit.: 134).

Ainda no século XIII, Egídio Romano - frei Gil de Roma - desempenhou um papel fundamental na reflexão sobre a atuação dos poderes. Esse pensador, com base no pensamento de São Tomás - que estabeleceu as relações que repercutiriam durante os séculos seguintes entre a fé cristã com o pensamento da Política de Aristóteles, revivendo as ideias de uma comunidade social mais humanizada e guiada pelo príncipe, pilastra da reorganização e comunhão da policie ${ }^{2}$-, definiu um caráter mais humano para as condutas e ações do governante (Cf. BUESCU, 1996: 36 e 37).

Esse período, os historiadores têm destacado como o momento de fusão da teologia com o pensamento aristotélico, direcionado às práticas do cotidiano. Também nesse momento forja-se o modelo medieval dos Espelhos de Príncipe (Ibidem: 39).

Muitos dos homens formados nessa geração da passagem do século XIII para o XIV elaboram suas doutrinas sobre a inter-relação entre os poderes e suas aplicações práticas, sempre retomando seus predecessores. Jean de Paris (1240?-1306), por exemplo, em sua De potestate regia et papali, reivindicou o caráter natural da sociedade civil. Desta forma, a Igreja não deveria dispor de direitos sobre as propriedades laicas, ou seja, caberia à Igreja não a posse, mas apenas administrar até mesmo seus próprios bens.

\footnotetext{
${ }^{1}$ A expressão "corpus mysticum", segundo Kantorowicz, representou a tentativa corporativista da Igreja em se colocar como única representante de Deus na terra, representando Cristo como a cabeça desse corpo. Cf. op. cit., p. 126.

2 A palavra policie (ou police) designava no medievo francês organizações ou comunidades políticas, administração pública, governo ou governação, Estado. A expressão politique (política) era aplicada normalmente como referência à ciência ou campo do conhecimento. Cf. Dictionnaire du Moyen Français (DMF). In: ATILF/Équipe "Moyen français et français préclassique", 2003-2005. Base de Lexiques de Moyen Français (DMF1). Disponível em: http://atilf.atilf.fr/gsouvay/scripts/g2/renvoi.exe?OUVRIR_MENU=6;BACK;s=33433560;lem=POLICIE;. Acesso em: 21 maio 2007.
} 
Nessa altura, interpretações aristotélicas dos corpos políticos e sociais deixaram de ser exclusividade da Escolástica do século XIII e passaram a ganhar terreno nos debates sobre a vida e a organização cotidiana nas estruturas de poder, dando início a discussões sobre os caminhos para uma política terrestre. Assim como Dante faria na segunda metade do século XIV, Jean de Paris esmiuçou o dualismo entre l'homo naturalis e l'homo christianus (Paris. Apud QUILLET, 2001: 19-21).

Já no início do século XIV, foi requisitado no Antequam essent clerici, de 1376 e de autoria anônima, o direito de maior controle sobre o espiritual pelos organismos laicos, antecipando os argumentos que mais tarde surgiriam, no Songe du Vergier, sobre os reagrupamentos dos poderes: “(...) A Igreja não pertence somente aos padres, mas também aos laicos (...)". ${ }^{3}$ Do mesmo período, o Rex pacificus Salomon e o Disputatio inter militem et clericum, de autores também anônimos: defenderam a unidade do poder em torno do príncipe; demarcaram as relações entre os poderes eclesiásticos e temporais; identificaram e opuseram uma série de termos em uma enumeração sistemática, de acordo com as categorias funcionais e composições orgânicas e espirituais da sociedade. Os súditos seriam, nesse contexto, a força motriz das ações do reino, entendido como uma substância temporal; e o rei, parte representativa de uma substância espiritual, seria responsável pela condução das ações práticas (Cf. QUILLET, 1977: 17).

Se esse pequeno esboço acerca dos textos produzidos do século XII até a primeira metade do século XIV adianta algo sobre um conjunto de relações que aos poucos foi ditando o ritmo de uma reordenação dos poderes nos finais da Idade Média, as produções textuais normativas e pedagógicas daí por diante passaram a redirecionar essas relações, ao se voltarem para o ideal governativo centrado na imagem do rei justo, forte e estável. Ao mesmo tempo em que seus autores discutiam o espaço destinado às atuações do poder eclesiástico, preconizaram o poder régio, pregando profunda lealdade a este e desenvolvendo trabalhos acerca da natureza de seus limites, direitos e deveres (Cf. KRYNEN, 1981: 325).

Assim sendo, é possível observarmos o aumento dessa produção, justamente nos séculos finais do medievo, que pode ser interpretado à luz de dois acontecimentos de extrema importância para a história do pensamento político medieval: primeiramente, o conflito entre monarquias e papado, que ganhou força a partir da conhecida querela entre Felipe IV e Bonifácio VIII em 1304, que resultou no Grande Cisma do Ocidente de 1378. Esse embate teria sido um dos fatores que levou os reis daquele período a estimular tipos de produções

\footnotetext{
${ }^{3}$ Anónimo. Apud QUILLET, 1977: p. 16. (Trad. nossa). Cf. “[...] l'Église n'appartient pas seulement aux prêtes, mais aussi aux laïcs [...]”.
} 
textuais que afirmassem sua soberania sobre as forças eclesiásticas; por outro lado, o processo de centralização dos poderes nas mãos dos monarcas e a (re)estruturação dos Estados medievais - especialmente durante o reinado de Carlos V - permitiu aos letrados de então que refletissem sobre as novas condições políticas imperantes e lançassem considerações acerca das conduções dos poderes. Ainda sobre a centralização dos poderes nas mãos dos monarcas, vale ressaltar que, considerando-se os lugares de onde falavam ou escreviam os letrados por meio de suas produções normativas pedagógicas do final do século XIV e início do XV, é importante a forma como foram sendo construídos os discursos desses homens a fim de reordenar os poderes. Para melhor identificar esse movimento, convém lembrar o surgimento de um aparelho administrativo regular e organizado, destinado a auxiliar o monarca em suas funções, composto por setores e pessoas responsáveis pela ordenação da governação do reino e cuidados com questões a ela referentes, bem como “(...) a instauração progressiva da fiscalidade pública e de uma ordem garantida pelo poder de comando do soberano" (CHARTIER, 2002: 216).

Aparentemente, a consolidação de tais mecanismos tornou-se possível graças à emergência das descritas novas formas de pensamento do final do século XII e início do XIII, voltadas para definir as virtudes reais exemplares para o bom exercício do poder, intercalando proposições jurídicas, teológicas e filosóficas e visando não somente a legitimação do poder régio, mas também a demarcação de limites e espaços que distinguissem e distanciassem os poderes eclesiásticos das competências régias (Cf. BLANCHARD, 1986).

Ainda no século XIII a linha que separava as duas instâncias de poder era muito tênue, não havendo um volume de escritos satisfatório que determinasse uma clara distinção entre elas. Será preciso esperar pelo século seguinte para que os letrados de então passem a elaborar um conjunto de escritos normativos que acentuem de fato essa demarcação. Apenas nos séculos finais do medievo é possível observar grandes debates e reflexões sobre a natureza e a prática dos poderes, quando os escritores que pensaram a vida política do período, especialmente aqueles que compuseram Espelhos, encontraram um solo fértil para uma produção textual que traduzissem suas ideias e servissem como orientações para aqueles que governavam.

Com base em uma concepção organicista da sociedade, e sendo o monarca a cabeça pensante desse corpo, ${ }^{4}$ a elaboração de doutrinas pedagógicas destinadas à formação do

\footnotetext{
${ }^{4}$ A ideia de uma sociedade representada como um corpo humano ganhou força com João de Salisbúria e seu Policraticus, onde cada um dos grupos sociais era ilustrado como seus braços, suas pernas, seu tronco e a cabeça.
} 
governante mostrou-se o objetivo dos mestres desse período, centrando-se em reflexões sobre a conduta e as funções destinadas ao rei - de modo geral, um deslocamento das formas de se pensar o poder da ordem contratual feudal para uma ordem estatal centralizada, sendo o monarca responsável por organizar o "corpo social” a partir de um corps de policie fortalecido e que atentasse para o "bem comum".

Entretanto, sendo o rei também humano, e por isso sujeito aos pecados e crimes gerados no interior do próprio corpo social, justificar-se-ia sua educação e a presença de um corpo de conselheiros que orientassem o monarca no caminho da "pura verdade", correspondente à perfeita arte de governar seu corpo, casa e reino. Assim, educar e aconselhar são funções fundamentais dessa produção normativa que ganha novos significados no século XIV(Cf. BLANCHARD, op. cit.: 43).

\section{Philippe de Mézières, Christine de Pisan e outros letrados: os poderes nos séculos XIV e XV}

Falar em "novos significados" para os escritos dos homens de saber, e de como esses pensaram seu universo naquele tempo, conduz a uma questão fundamental dos tratados do final do século XIV para o XV, isto é, não estavam seus formuladores preocupados somente com a afirmação da monarquia como regime ideal, mas, antes de tudo, com a exposição dos caminhos necessários que conduziriam a uma forma salutar de governança, onde a chave para esse objetivo era o próprio monarca.

Ao se elaborar um discurso pedagógico destinado ao príncipe ou monarca, consequentemente atingir-se-ia a boa organização e pacificação do reino. Sendo assim, essa modalidade discursiva do período, como tem apontado os historiadores, participou dos rumos tomados na reordenação dos poderes, trazendo um novo sentido e classificação para as virtudes e os atos políticos e sociais.

Ao definir caminhos para a "perfeita governação", os letrados do final do medievo também elaboraram fórmulas de aplicação prática da science de politique e suas relações com a arte de governar. Foi com esse intuito que Christine de Pisan elaborou seu tratado sobre a vida de Carlos V, vendo nesse rei um modelo a ser seguido:

Por isso que a science de politiques, superior entre as artes, ensina o homem a governar a si mesmo, como servo e súdito, e todas as coisas, conforme ordem justa e certa; como ela é disciplina e instrução de governar os reinos e impérios, todos os povos e todas as nações (...): visivelmente esse sábio 
príncipe (...) conhecedor daquela ciência, (...) pela prudência de seu informado/prevenido entendimento, ele aprende naturalmente, sem outra leitura apreendida nessa parte: pois sua pessoa governou por pollicie ordenadamente, como dito está (PISAN, 1824, tomo V: 283). ${ }^{5}$

Assim foram os Espelhos de Príncipe, “(...) um instrumento de revelação que os clérigos oferecem aos soberanos (...)" (BLANCHARD e MÜHLETHALER, 2002: 07). Modelo discursivo tido como um importante instrumento de valorização das virtudes para a salvação do espírito e as limitações dos poderes régios com base nas leis divinas, estabelecendo, com isso, uma estreita subordinação da monarquia às doutrinas da Igreja Católica.

Nesse processo que culmina em construções discursivas centradas na figura régia encontra-se uma alteração significativa nas formas de representação e interpretação dos poderes. Se até o século XIII o debate sobre o poder esteve circunscrito em reflexões que o determinavam como uma vontade divina, e nesse caso ele foi entendido como uma responsabilidade eclesiástica, estabelecendo com isso um forte vínculo do poder temporal ao espiritual, no século XIV tais reflexões foram direcionadas a pensar essa relação de outra forma. Os letrados passaram a defender não somente o monarca, mas todo o corpo secular como responsável pelo trato com o as instancias temporais, limitando, com isso, o campo de atuação dos poderes eclesiásticos. Se for possível observar nesse século um processo contínuo de transformações pelos quais passou o pensamento medieval, igualmente se poderão perceber na segunda metade desse século, mais especificamente durante o governo de Carlos $\mathrm{V}$, novas configurações no papel dos tratados normativos. Seus autores se voltaram para a figura monárquica como pilastra fundamental na condução do poder e passaram a enxergar nas ações do governante régio as virtudes constitutivas necessárias para se alcançar o ideal de "perfeito monarca".

Foi igualmente importante nesse instante a valorização dada aos letrados medievais como portadores de verdades, posição de grande importância para aqueles que passaram a ditar normas para a condução política. De modo geral, é possível perceber a emergência dessa relação com a verdade a partir de dois fatores: inicialmente pelo lugar que ocuparam tais letrados e suas obras. Especialmente no governo de Carlos V houve um estimulo a produção

\footnotetext{
${ }^{5}$ (Trad. nossa). Cf. "Pour ce que la science de politiques, superllative entre les ars, enseigne homme à gouverner soy mesmes as mesgniée et subgiez et toutes choses, selons ordre juste et limite; comme elle soit discipline et instruccion de gouverner royaumes et empires, tous peuples et toutes nacions [...]: apert manifestement cestui sage prince estre [...] expert en ycelle science, [...] par la prudence de son averty entendement, luy aprrenoit naturellement, sanz autre estude de lettreure aprise en ceste partie: car sa personne governoit par pollicie tres ordennée, comme dit est".
} 
escrita e de traduções de gêneros diversos e de campos do saber distintos como filosofia, teologia, direito, etc. $\mathrm{O}$ estimulo a essa produção, juntamente com a volumosa entrada desses homens de saber nas cortes e em funções públicas, propiciou novas formas de abordar e de pensar o poder. Nesse caso, a noção de verdade teve um papel fundamental. Não somente passaram a orientar o monarca nos caminhos da perfeita governação como a voz de seus discursos ganhou novo peso por meio da importância da palavra escrita e oral, que passaram a possuir um novo significado. Ela passou a ser um forte - se não o maior - instrumento transmissor de "verdades". Nomes como Philippe de Mézières, Jean Gerson, Juvenal de Ursins, Christine de Pisan, entre outros, foram exemplos daqueles que se empenharam em apresentar verdades entre o final do século XIV e início do XV; pessoas que tiveram o privilégio de traduzir em linguagem pedagógica as estruturas de poder até então propostas. Nesse caso, o lugar ocupado por esses homens foi o que lhes possibilitou uma visão privilegiada como testemunhos diretos das ações e acontecimentos nas esferas de poder.

Um segundo fator que contribuiu para essa posição dos letrados como portadores de verdades pode ser percebido na forma como sustentaram seus discursos, isso é, por meio do reencontro com a espiritualidade cristã. $\mathrm{O}$ discurso, que em outro momento separou os poderes, orientou o monarca no final do século XIV a se reaproximar da Igreja e defende-la. Todo o conjunto de virtudes salutares ao bom governo foi proposto em acordo com a doutrina cristã - o rei deveria ser não somente sábio, mas também defensor da fé em nome do "bem comum". Ocorreu, portanto, uma inversão na ordenação das forças políticas, pois, na visão dos letrados de corte e de muitos eclesiásticos, o rei passou a ser responsável pelo cuidado com a instituição eclesiástica. Se até o século XIII os poderes régios foram dependentes e submissos aos homens da Igreja, nos séculos seguintes o monarca torna-se, na menor das hipóteses, o guardião direto de seus valores.

Como exemplo específico do que foi dito até então pode ser citado Philippe de Mézières (1327-1405), que foi um homem de grande participação nos assuntos políticos e militares da França do final do medievo. Dedicou praticamente toda sua vida a cargos e funções públicas, tanto na França como em outros reinos da Europa. Sua infância foi breve, pois, em 1339, já servia como combatente nas forças de Lucien Visconti (1287-1349), nobre senhor de Milão, na batalha de Parabiago na Lombardia e, na seqüência, a André, duque da Calabria (?-1345), a quem serviu até a morte deste nobre.

No ano de 1346, é armado cavaleiro em Jerusalém, após participar de uma ofensiva francesa contra os povos do Oriente Próximo. Anos mais tarde, inspirado por essa investida contra os infiéis, iniciou a escrita de seu Nova religio passionis, entre 1367 e 1368, 
concluindo-a apenas em 1396, quando a traduziu para o francês e deu-lhe o título de $L a$ Chevalerie de la Passion de Jhesu Crist. Nesta obra, Mézières descreve uma suposta revelação que teve e o levou a estabelecer os fundamentos para a criação de uma nova ordem de cavalaria, ordem essa que, embora não tenha tido adeptos ou simpatizantes durante aqueles anos da década de sessenta, não minimiza o interesse da obra para os homens do período, tendo em vista o interesse que ainda gerava a ideia de retomada das "grandes cruzadas" (Cf. MENUT, 1970: 12 e 13).

Algumas das suas principais ideias políticas foram forjadas com base em sua crença (ou sonho como o próprio letrado definia) da necessidade de uma nova cruzada dos reinos do Ocidente contra os mouros na Terra Santa que ele defendeu em sua obra de maior importância chamada Le Songe du Vieil Pelerin (1381-1389). Uma obra alegórica onde Mézières descreve um momento de grande crise que assolava a Europa cristã no final do medievo, crise essa representada nas suas guerras, fomes e outras calamidades que marcaram o período. Segundo o "velho peregrino", estas consequências terríveis na vida dos homens cristãos daquela época tiveram sua origem em um acontecimento maior: a fragmentação da Cristandade resultante da cisão da própria Igreja em duas e em suas desavenças com os monarcas, especialmente, franceses. Como solução para tais problemas o letrado vislumbrou em uma nova cruzada, que reunisse todos os reinos da Cristandade e, na qual o reino da França teria liderança direta, a possibilidade de pacificar a Europa cristã através da luta contra o infiel.

No ano de 1372, quando retornou em definitivo para a França, Mézières, conheceu Nicolau Oresme, ilustre conselheiro de Carlos V. Apesar de ter em Oresme um grande amigo e admirador, Mézières não conseguiu convencer o monarca francês a promover seu ideal cruzadístico contra os árabes. Entretanto, foi tutor do então príncipe e delfim Carlos, futuro Carlos VI, oportunidade que teria lhe dado condições de, quem sabe, influenciar o futuro monarca com suas ideias sobre a necessidade de uma Cruzada em direção ao Oriente. Mas a morte de Carlos, o Sábio, em 1380, e a ascensão prematura de Carlos VI ao trono - o jovem monarca não contava doze anos quando tomou posse da coroa francesa - resultou em um governo de regência dirigido pelos seus tios João de Berry e Felipe II da Borgonha, que afastaram o letrado das ações de comando e tutela do jovem rei. Foi nessa época que Mézières se retirou para o convento dos Celestinos em Paris, onde passaria alguns anos de sua vida.

Durante esse período, apesar do claustro, continuou a participar da vida política francesa, comunicando-se com o jovem monarca e produzindo algumas de suas mais importantes obras, como Contemplatio horae mortis e Soliloquuum peccatoris, ambas concluídas em 1387, e o próprio Le Songe du Vieil Pelerin. Com a maturidade do monarca, no 
final da década de oitenta do século XIV, teve fim o período de regência e Carlos VI deu início ao seu controle sobre o reino, afastando definitivamente seus tios das decisões políticas. Nesse instante, Philippe de Mézières volta a ter acesso à corte e a aconselhar o rei de forma direta.

O interessante é notar que toda essa trajetória descrita indica dois momentos na vida desse letrado, embora sempre com uma mesma ideia fixa: a proposta de Cruzada em direção ao Oriente. Em um primeiro momento, anterior ao seu retorno definitivo para a França (1372), Mézières procurou fundar sua própria Ordem e tentou receber o apoio da Igreja para levar adiante seu projeto. Nessa época, ele atuou como conselheiro e cavaleiro, participou e conheceu diversos reinos da Cristandade e do Oriente. Atuou diretamente nos acontecimentos políticos de muitos dos reinos pelos quais passou e projetou sua proposta para a salvação da Cristandade: a pacificação entre os cristãos na luta contra os infiéis (JORGA, 1896: 34). Em um segundo momento, quando regressou à França, sua ótica sobre como reunir o povo cristão em torno de seu projeto de Cruzada sofreu uma importante modificação no que diz respeito ao ponto de referência. Se antes ele vislumbrava na Igreja a instituição responsável por estimular a comunidade cristã a se organizar em grupos, ou ordens autônomas, para partir em defesa dos seus interesses, nesse instante de sua vida, sua obra caracteriza-se por evidenciar a figura do monarca como referência para liderar e consolidar seu projeto.

Essa noção de centralização dos poderes e de reformas do reino manifestou-se na obra de Mézières, e de outros letrados, pelo esboço de normas de condutas morais a serem seguidas pelos reis cristãos, assim como seu dever em amar e adorar a Deus, ressaltando a importância de “(...) ter uma doce memória e em teu coração dar graças a Deus” (MÉZIÈRES, 1969, vol. 2: 123$){ }^{6}$ pois esse era o caminho para se promover “(...) a reforma da cristandade e multiplicação dos talentos comuns dos cristãos e da fé católica" (Ibidem, vol 1: 88). ${ }^{7}$ Como diz a Rainha Verdade, uma das personagens alegóricas centrais no Le Songe (...), ao jovem monarca francês: “(...) por graça e por teu livre arbítrio tu recebeu em toda prosperidade, à tua direita, minha muito amada camareira Humildade e, à tua esquerda, em toda adversidade Paciência, tu és capaz e digno da graça de Deus" (Ibidem, vol. 2: 128). ${ }^{8}$ Ao expor e explicar as virtudes divinas extraídas das Sagradas Escrituras e das narrativas bíblicas, Philippe de Mézières exaltou a figura régia como peça essencial para a reafirmação do pensamento

\footnotetext{
${ }^{6}$ (Trad. nossa). Cf. "[...] avoir une doulce memoyre et en ton cuer [ o de Carlos VI] rendre grace a Dieu".

${ }^{7}$ (Trad. nossa). Cf. " [...] la reformation de la crestiente et multiplication du besant commun des crestiens e de la foy catholique".

${ }^{8}$ (Trad. nossa). Cf. "[...] par grace et par ton franc arbitre tu as prins en toute prosperite a ta dextre ma tresamee chambriere Humilite et a ta senestre en toute adversite Pacience, tu es cappable et comprenable de la grace de Dieu".
} 
cristão, assim como também o fez Raul de Presles em 1369, com seu Discurs sur l'oriflame, definindo o príncipe como figura "cristianíssima, combatente para uma justa causa", que deveria depositar todas suas confianças em Deus (Cf. Presles. Apud BOUTET e STRUBEL, 1979: 161). Mesmo no século XV, quando a organização dos Estados chegou ao seu momento máximo, não havia qualquer interesse entre os homens do período em limitar a soberania régia, ou mesmo, em conceder habilitações a qualquer outro grupo social no cuidado com os súditos, pois, sancionar a autoridade monárquica correspondia a "violar sua missão de justiça e paz” (KRYNEN, 1993: 360). No caso de Mézières, portanto, o rei se destacou como mediador fundamental para o alcance de suas expectativas de unir os reinos do Ocidente em uma causa comum. Uma nova motivação para os homens do final do século XIV era a pacificação e a reconciliação entre os governos e reinos do Ocidente, envolvidos em guerras e conflitos internos. ${ }^{9}$ Em razão desses acontecimentos e lutas, Mézières acreditava que o Ocidente passava por uma crise. Se cristãos estavam envolvidos em batalhas entre eles mesmos, isso significava que os valores do cristianismo estavam sendo esquecidos. A mesma percepção sobre os problemas do período é apresentada por Jean Gerson:

(...) para os pecados do corpo místico, seja no chefe, seja nos membros, nós encontramos adversidades corporais e civis e, especialmente, quando estes são pecados horríveis, desagradáveis e grosseiros contra Deus e a natureza. Para essas guerras, para esta fome, para estas pestilências, para estas revoltas e divisões (...) não há melhor conselho do que ter boa vida espiritual tanto o Rei como seus súditos (GERSON, 1990, 18). ${ }^{10}$

Retomando a discussão sobre como os poderes seculares passaram a ser valorizados em detrimento das forças eclesiásticas, é de igual valor o pensamento de Alain Chartier (1385-1449). Suas obras alegóricas, poéticas e em prosa, teve como maior interesse a didática moralizante. Em uma de suas obras mais importantes, seu tratado em prosa Quadriloge Invenctif, dedicado à exposição de virtudes ligadas à nobreza francesa, ele salientou a necessidade da paz entre as esferas através do diálogo entre os membros da comunidade temporal com os representantes da instituição eclesiástica. Suas representações alegóricas: o

\footnotetext{
${ }^{9}$ Só para ilustrar alguns destes eventos, podemos relembrar o Grande Cisma de 1378; o conflito na cidade de Paris após a prisão de João II pelos ingleses (1356), em que os mercadores e nobres da cidade entraram em desacordo pela legitimação do governo do, então, delfim Carlos, em que foi preciso convocar a reunião dos Estados em assembléia no mesmo ano para se definir uma solução; os Jacquerie, em 1358; e a tão conhecida Guerra dos Cem Anos (1337-1456).

${ }^{10}$ (Trad. nossa). Cf. "[...] pour les pechez du corps myftiq, foit en chef, foit en mébres nous viennét aduerfitez coprporeles \& ciuiles, \& par especial quãd ce font pechez horribles, eftráges, ors \& vilains contre Dieu \& nature. Pour ce guerres, pource famines, pource peftiléces, pource feditiõs \& diuifiõs [...] n'eft plus beau confeil d'avoir bõne vie fpirituele tant au Roy, comme es fubiects".
} 
Reino da França, o Cavaleiro, o Povo e o Clérigo, as quais têm suas virtudes apresentadas a partir das interpretações dos seus feitos. Todo debate é travado com argumentos que defendem a legitimidade da autoridade régia e secular sobre os domínios da Igreja. Outro já citado pensador desse mesmo período, por exemplo, Jean Gerson passou a exaltar o monarca como o responsável por reformar a "espiritualidade e temporalidade da Igreja da França" (Ibidem: 45), nesse momento em que "a ruína da Igreja” é tema recorrente. Considerava-se que a Igreja e a Cristandade não somente estavam corrompidas pela má vontade e desagrados dos seus membros, mas também sofria com a cisão provocada pela proclamação de dois papas. Nicolas de Clamanges, em 1402, chega mesmo a defini-la como uma instituição repleta de vícios (Cf. CLAMANGES, 1936). Concomitantemente, letrados, como Nicolau Oresme, Juvénal de Ursins, Philippe de Mézières e Jean Gerson, buscaram pensar como deveria ser conduzida a reforma do governo da Igreja (Cf. KRYNEN, 1993: 373) com a colaboração dos soberanos régios - reconhecidos como protetores legítimos da instituição. Para Philippe de Mézières, cabia a Carlos VI reunir um concílio que poria fim ao Grande Cisma (Cf. MÉZIÈRES, 1969, vol.2: 292-298). De forma semelhante, em 1391, Gerson chamou a atenção do jovem rei francês para os infinitos males, espirituais e temporais, que denunciavam “a divisão dos cristãos” (Cf. KRYNEN, 1993: 374).

O mesmo discurso reconciliador apresentou-se em algumas reflexões e propostas lançadas por Christine de Pisan (1363-1430) no início do século XV. Entretanto, a construção desta letrada da imagem do monarca como intermediador nos conflitos entre monarquia e Igreja seguiu um rumo diferente daquele proposto pelos letrados do século XIV. Seu discurso pregava que o monarca deveria voltar-se para si mesmo, pesar suas ações e rever determinadas estruturas de seu governo a fim de reorganizar a política do reino. Enquanto muitos dos homens do século anterior ao dela pregavam que o rei deveria voltar-se para os problemas que assolavam o reino por meio do diálogo com o clero - como Jean Gerson ou Alain Chartier - ou através de ações que reunificassem os reinos da Europa cristã em uma mesma comunidade maior, a Cristandade - Philippe de Mézières -, Christine de Pisan propôs um movimento contrário para o monarca. Encontrar soluções para os problemas vigentes através de uma análise sobre si mesmo.

Nas diversas facetas que assumiu os conselhos oferecidos aos monarcas da França por meio dos Espelhos, a condição sacralizada do monarca ocupou um papel central. As obras políticas de Pisan, por exemplo, dissertam constantemente sobre a condição divina do monarca. A atualização que ela faz do tema talvez seja sua maior diferença em relação, por exemplo, à Mézières. Se este letrado, no final do século XIV, traduziu a figura régia a partir 
dos escritos bíblicos, vinculando a imagem do jovem Carlos VI com a personagem religiosa do profeta Moisés, sem diferenciar exatamente uma da outra em seu tratado, revivendo em sua época, de Mézières, os tempos bíblicos, Christine de Pisan trata da pessoa de Carlos V de forma isolada em seu Espelho sobre a vida e os feitos desse governante, como se quisesse descolar a imagem desse monarca de qualquer outra personagem histórica. Seu uso do passado serve como tradução e exemplos de seu pensar político para seus leitores (Cf. GAUVARD, 1995: 21). Para ela, as ações e os feitos do rei "sábio" durante sua vida e governo são demonstrações de que, por vontade divina, ele foi digno de ocupar o cargo máximo no reino da França, assim como por suas "perfeições mundanas" e por seu "sangue valoroso"; estando, pois, abaixo apenas de um único governante, Deus, cujo "alto nome se fez conhecer sobre todos os príncipes morais" (PISAN, 1824, tomo VI: 02). ${ }^{11} \mathrm{Na}$ verdade, ao escrever este tratado direcionado à formação de futuros governantes, ela se dedicou a traçar um perfil que deveria ser característico de todo monarca. Carlos V foi o modelo de tal perfil, por terem sido seu governo e vida exemplos que correspondiam às ações que ela desejava encontrar em qualquer homem daquela posição. Por isso, mais do que enaltecer a figura deste governante, Pisan procurou traçar seu modelo para que servisse como ensinança para gerações futuras de príncipes e nobres. Ela procurou identificar um conjunto de práticas comuns que, quando executadas pelos príncipes, atenderiam ao que a vontade divina projetava para uma perfeita organização política. Consequentemente, todos que adotassem tal modelo poderiam chegar a ser reconhecidos como governantes exemplares. Enquanto Mézières vislumbrou e fixou em Carlos VI um modelo específico de monarca com uma missão ou função prédefinida por um desígnio maior, a salvação da Cristandade, Christine de Pisan tomou de empréstimo o modelo de governo de Carlos, o Sábio, para descrever e ensinar os caminhos que conduziriam a um perfeito reinado. Essa percepção sobre o ofício régio não está somente presente no Livre des fais... Ela também anuncia sua ânsia por um bom governante ao expor as imagens principescas em seu Livre dus Corps de Policie:

Quando o filho do príncipe cresce e chega à idade ou ao tempo em que deve governar e já pode compreender sua herança por sucessão (...) se deve demonstrar nele e se manifestar a perfeição das virtudes, a exemplo do sábio rei da França, Carlos, o quinto (...) (PISAN, 1998: 08 e 09). ${ }^{12}$

\footnotetext{
11 (Trad. nossa). Cf. "hault nom dénoncé sur tous princes mortelz".

12 (Trad. nossa). Cf. "Quant le filz du prince est parcreu et venu en aage et ou temps qu'il doit seigneurir et qu'il est ja saisy de son heritaige par succession, [...] se doit demonstrer en lui et aparoir la parfeccion de vertu, a l'exemple du saige roy de France, Charles le quint [...]".
} 
E ela continua:

(...) especialmente em três coisas se devem demonstrar as virtudes do príncipe (...) a primeira e principal, amar a Deus (...) e o servir por boas obras (...); ele deve amar o bem e o desenvolvimento de seu país e de seu povo (...). A terceira é que, soberanamente, ele deve amar justiça (...) e deve equalizar toda pessoa (Ibidem). ${ }^{13}$

Para ambos os letrados, portanto, era fundamental aos governantes régios servir e realizar os desígnios divinos na terra, porém, enquanto o primeiro articula e combina a figura do monarca com uma personagem histórica, procurando com isso afirmar sua condição sacralizada e dar razão aos seus planos de investidas ao Oriente, a segunda procurou desenhar um exemplo de governante sacro a partir de um modelo de seu tempo, constituindo com isso uma forma de representação do poder que não encontrava sua legitimidade em valores préestabelecidos, mas sim nos seus feitos durante sua vida.

Assim sendo, os letrados franceses deste período, por meio de certos instrumentos discursivos, acabam por descrever parte do passado da França na passagem do século XIV para o XV, e suas obras culminam em uma mesma resposta para os problemas de seus tempos e para legitimar seus projetos, fosse para a Cristandade, fosse para a França: o rei como representante e submisso somente a Deus. Não era suficiente traduzir para o monarca quais eram suas principais obrigações, era preciso dar à função régia um sentido que justificasse que essas obrigações fossem exercidas. Ao traçarem esse perfil do monarca, Philippe de Mézières, Christine de Pisan, Jean Gerson, entre outros letrados, determinaram o espaço de atuação do poder secular: o monarca deveria ser representante da palavra divina, servindo como modelo moral para os fiéis ou seus súditos, e garantir a segurança e a paz entre os homens de Deus. Se esses dois letrados sublinharam a importância da reaproximação das ordens temporais com a Igreja, depois do Grande Cisma de 1378, ao mesmo tempo atribuíram ao rei a função de transmitir para seus súditos aquilo que era a vontade de Deus. Por essa razão, o rei deveria ter total controle sobre seu reino e conhecimento total deste, ou, no caso de Philippe de Mézières, controle sobre a Cristandade. Se a proposta desses homens de saber era a formulação da imagem de um governante exemplar, a caracterização do monarca como representante direto de Deus na terra concluía o processo de construção desta figura, pois, afirmar o caráter divino da monarquia foi o meio de legitimar não somente a autoridade régia, mas também o próprio

\footnotetext{
${ }^{13}$ (Trad. nossa). Cf. "par especial en trois choses se doit demonstrer la vertu du prince [...] la premiere et principal, aimer Dieu [...] et le servir par bonnes oeuvres [...]; il doit aimer le bien et l'acroissement de son pays et de son peuple [...]. Le tiers est que souverainement il doit aimer justice [...] et doit faire éqüite a toute gent".
} 
discurso de cada um dos letrados. Era por determinação divina que o rei deveria se voltar para a Cristandade ou para as condições de seu próprio reino. Foi com base nessa concepção religiosa da imagem e da função monárquica que Philippe de Mézières e Christine de Pisan, por exemplo, puderam solidificar suas interpretações sobre aquilo que acreditavam ser o ofício régio: o monarca deveria ser cristianíssimo e ter em mente sua "missão profética" herdada do passado glorioso de seus antecessores.

\section{Referências Bibliográficas:}

BLANCHARD, Joël. L'entrée du poète dans le champ politique au XVe siècle. Annales. Histoire, Sciences Sociales. Paris, Éditions de l'EHESS, Vol. 41, no 1, p. 43-61, 1986.

2002. ; MÜHLETHALER, Jean-Claude. Écriture et Pouvoir. À l'aube des temps modernes. Paris: PUF,

BOUTET, Dominique; STRUBEL, Armand. Littérature, politique et société dans la France du Moyen Age. Paris: 1979.

BUESCU, Ana Isabel. Imagens do príncipe. Discurso normativo e representação (1525-1549). Lisboa: Edições Cosmo, 1996.

CLAMANGES, Nicolas de. Le Traite de la ruine de l'Eglise de Nicolas de Clamanges et la traduction francaise de 1564. Paris: Droz, 1936.

GAUVARD, Claude. L'autorité dans les traités em prose de Christine de Pizan: Discours d'écrivain, parole de prince. DULAC, Liliane ; RIBÉMONT, Bernard (eds.). Une femme de Lettres au Moyen Age. Étude autour de Christine de Pizan. Orléans: Paradigme, 1995

GERSON, Jean. Harengue faicte au nom de l Université de Paris devant le Roy Charles sixiesme, \& tout le conseil contenant les remonstrances touchant le gouvernement du Roy [Documento eletrônico] / [par maistre Jehan Gerson]. Num. BNF da éd. de Cambridge (Mass.): Omnisys, 1990, Coleção French books before 1601; 88.10. 1 microfilme reprod. da éd. de Paris: por Vincent Sentenac, 1561. Número de referência na biblioteca da França: FRBNF37254940.

JORGA, Nicola. Philippe de Mézières, 1327-1405, et la croisade au XIV siècle. Paris/Genova: 1896/1976.

KANTOROWICZ, Ernest H. Os dois corpos do rei: um estudo sobre teologia política medieval. São Paulo: Companhia das Letras, 1998.

KRYNEN, Jacques. Idéal du prince et pouvoir royal en France à la fin du Moyen Age (1380-1440). Etude de la littérature politique du temps. Paris: Picard, 1981. 1993.

L'Empire du roi. Idées et croyances politiques em France, XIII-XVe. Siècles. Paris: Gallimard,

MENUT, Albert Douglas. Maistre Nicolau Oresme: Le Livre de Politiques d'Aristote. Publicação a partir do Text of the Avranches Manuscript 223. Filadélfia: American Philosophical Society, 1970.

MÉZIÈRES, Philippe de. Le Songe du Vieil Pelerin. Editado por George W. Coopland. Londres: Cambridge University, 3 Livros, Vols. 1 e 2, 1969.

PISAN, Christine de. Le livre des fais et bonnes meurs du sage roy Charles V. In: PETITOT, M. (org.). Collection complète des mémoires relatifs a l'histoire de France, depuis le règne de Philippe-Auguste, jusqu'au commencement du dix-septième siècle. Paris: Foucault, Libraire, Ruede Sorbonne, Tomos V e VI, 1824. 
Champion, 1998

Le livre dus corps de policie. Ed. crítica com introd. e notas de Angus J. Kennedy. Paris: Honoré

QUILLET, Jeannine. La philosophie politique du songe du vergier, 1378: sources doctrinales. Paris: J. Vrin, 1977. . D’une cité l'autre: problèmes de philosophie politique médiévale. Paris: H. Chapion, 2001.

SALISBÚRIA, João. Policraticus. Cambridge University Press, 1990. 